www.jmscr.igmpublication.org

Impact Factor 5.244

Index Copernicus Value: 83.27

ISSN (e)-2347-176x ISSN (p) 2455-0450

crossref DOI: _https://dx.doi.org/10.18535/jmscr/v4i10.59

\title{
Benign Tumors Mimicking Sarcoma Clinically - 3 Case Reports
}

\author{
Authors \\ Rari Padma Kumari Mony, Sindhu Nair P, Thara Somanathan, Anitha Mathews, \\ Jasyasree K.
}

\section{ABSTRACT}

We report three cases in different sites clinically presented as soft tissue sarcoma, but histopathology turned out to be benign tumors. Sites of the tumors are in unusual location, with relatively short duration from clinical presentation. All the cases ends in complete exicision for final diagnosis. These cases also serve as a reminder that coon complaints can be a sign of significant pathology.

\section{INTRODUCTION}

Neoplastic mimics or "pseudo tumors" can simulate neoplasm on all levels of analysis on clinical, radiological and pathological basis. Thus represent particular diagnostic pitfalls for the pathologist that can ultimately lead to therapeutic mis-directions.

\section{CASE 1}

A 19 year old male presented with swelling left upper abdomen for 5 years. CT Scan shows $8 \times 7 \times 7.7 \mathrm{~cm}$ parietal swelling with calcification. Radiologial impression was Chondroma/ Parasitic. Trucut biopsy taken twice both shows few adipocytes, scattered marrow elements and fragments of muscle bundles.

Based on this histomorphology, a haematological workup including bone marrow aspiration and trephine biopsy were performed to rule out any underlying haematological disorders. Bone marrow aspiration and trephine were normal without fibrosis. Wide exicision was done shows a skin covered soft tissue measuring $12 \times 11 \times 5 \mathrm{~cm}$. Cut section shows circumscribed hard bony tissue with whitish tan colour glistening areas measuring $10.5 \mathrm{x} 9 \times 8 \mathrm{~cm}$. Centre of the lesion spongy and hemorrhagic. Microscopy shows bony spicules, cartilage, adipocytes and bone marrow elements. Based on this myelolipoma - anterior abdominal wall was diagnosed.

Rare tumor described in 1905 by Gierke ${ }^{(1)}$ and named by oberling in 1929. Most myelolipoma occurs in adrenal gland where they are typically non- functioning and asymptomatic, but large lesion can be symptomatic due to mass effect and haemorrhage. Myelolipoma are mesenchymal tumor composed of admixture of fat and bonemarrow derived haemopoietic elements. Mean size of extra adrenal myelolipoma is $8.2 \mathrm{~cm}$. The hypothesis of the cause of the myelolipoma include degenerative changes in the hyperplastic tumor cells or adenoma of adrenal gland, metaplasia in the primary mesenchymal stem cells of the adrenal gland and displacement of differentiated bone marrow cells during embryogenesis ${ }^{(2)}$. Some authors suggest metaplasia of reticuloendothelial cells caused by prolonged stress, inflammation, ACTH over excreation or development of 
myelolipoma from blood borne embolic material (3)

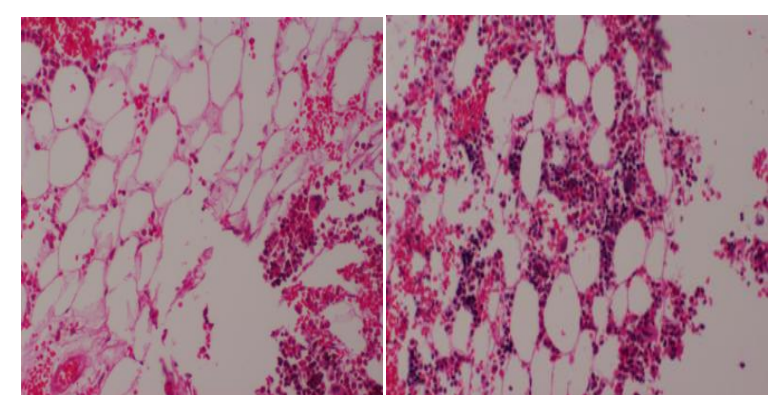

Fig.1 H\&E (100x) section showing mature adipocyticelements, erythroid, granulocytic precursors and megakaryocyte.

Histologically extra adrenal myelolipoma should be differentiated from mass forming foci of extra medullary hemopoiesis. Mass forming extra medullary haemopoeisis is symptomatic and is associated with myeloproliferative disorder, hemolytic anemia or sever skeletal disease ${ }^{(4,5)}$. These lesions can have predominant fat components and are more conspicuous lymphocytic population. This is distinct from true bonemarrow in that no reticular sinusoids/bone spicules are present. However if present, they consider the bone spicules to be the result of osseous metaplasia ${ }^{(6)}$.

\section{CASE 2}

A 73 year old female presented with a mass in the cubital-fossa. No history of pain, numbness or any trauma. CT done shows 9x8cm solid and cystic mass in the flexor aspect. Neurovascular bundle not involved. Mass is seen encasing head and neck of radius with cortical erosion. Radiological differentials are malignant fibrous histiocytoma / Nervesheath tumor. No previous medical or surgical history.

Wide exicision was done shows soft tissue measuring 9x7.5x7.5cm. Cut section solid, grey white lesion with friable areas and cystic areas. Microscopy shows extensive necrosis with periphery showing inflammatory infiltrate with foreign body giant cell reaction and granuloma. In view of clinical, radiological and histomorphological characteristic possibility of chronic osteomyelitis is favoured. Following the exicision, patient is on regular follow up for 2 years. No other complaints.

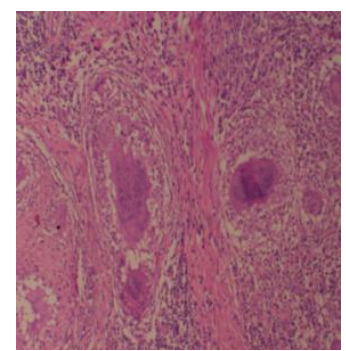

Fig.2, H\&E 200X showing granuloma formation and foreign body giant cell reation

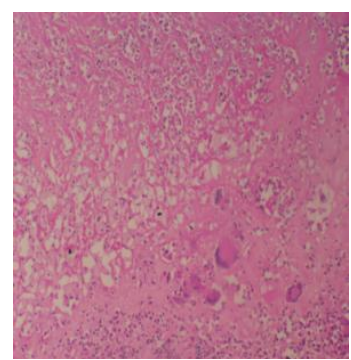

Fig 3 H\&E 200X showing extensive areas of necrosis.

It is an infrequent cause of soft tissue mass and is usually diagnosed clinically by combination radiology and microbiology.Numerous spindle cell proliferation can mimic sarcoma, spindle cell carcinoma, spindle cell melanoma, pseudosarcoma like nodular fasciitis, fibromatosis, and inflammatory myofibroblastic tumors. Due to its bone distruction it can mimic primary bone tumor (7). Chronic Osteomyelitis persist as long as infected dead bone remains. The dead bone is surrounded by granulation tissue that attack the sequestrum. Surgical removal of the sequestrum at the proper time allows the osteomyelitis to heal ${ }^{(8)}$.

\section{CASE 3}

Patient is a 20 year old female presented with fever and diagnosed to have pulmonary embolism, no history of DVT. Diagnosed to have pulmonary tuberculosis started ATT (CATGORY1). Patient on warfarine noticed a large swelling in the left thigh. Radiologically mass of size $14 \times 11 \times 9 \mathrm{~cm}$ with a differential diagnosis of liposarcoma.

Wide exicision specimen showing skin covered soft tissue measuring $15 \times 11 \times 9 \mathrm{~cm}$ and skin measure $12 \times 3.5 \mathrm{~cm}$. Cut section well encapsulated 
globular yellowish mass just beneath the subcutaneous fat measure 10x8x6cm. Microscopy shows fat cells with multi-vacuolation, granular eosnophilic cytoplasm. Areas of calcification present.

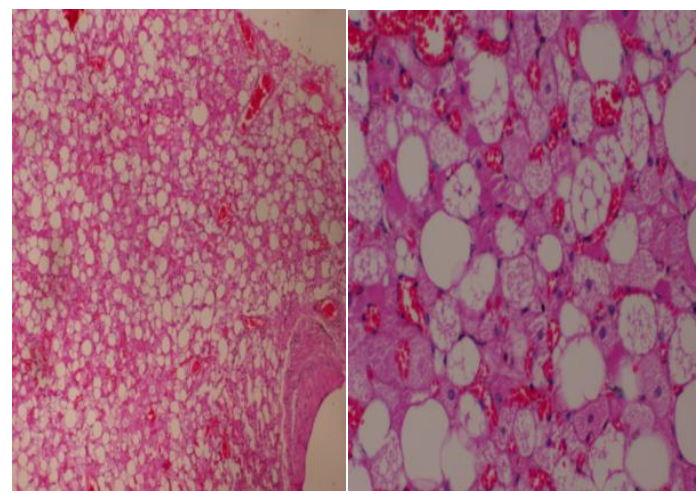

Fig 4 H\&E (200X,400X) fat cells with multivacuolations, granular eosnophilic cytoplasm.

Velsch was the first investigator to recognize the distinction between brown and white adipose tissue ${ }^{(9)}$. In 1914, the actual term hibernoma was coined when, Grey recognized a histological resemblance between these tumors and brown fat,he identified in hibernating animals ${ }^{(10)}$. PET imaging is useful in the scenario of the commonly encountered lipomatous lesion because it may be distinguish the simple lipomatous that have minimal metabolism from those lesion that may have a higher metabolic rate such as hibernoma and malignant liposarcoma ${ }^{(11)}$.

It is stated that this tumour are adequately treated by local excision, as the neoplasms are histologically and clinically benign but the extensive vascularity may cause troublesome bleeding in some instances ${ }^{(12)}$. This case echoes the importance of incorporating hibernoma in the differential diagnosis.

\section{CONCLUSION}

Three different cases are presented in the paper, all the cases presented as large space occupying lesions, that they have little clinical consequences. Pathologist need to be familiar with their existence to not to over interpret their clinical significances. All cases needs complete excision for final diagnosis, that itself leads to the complete treatment.

\section{REFERENCE}

1. Gierke E.Unusual myeloid tissue in the adrenal gland. Beitr Pathol Anat. 1905:3:11-25.

2. Dieckmann KP, Hamm B, Pickartz $\mathrm{H}$ et al. Adrenalmyelolipoma:clinical, radiological and histologic features. Urology 1987; Jan; 29(1): $1-8$.

3. Wilhelmus JL, Schrodt GR, Alberhasky MT, Alcorn MO. Giant adrenalmyelolipoma: a case report ad review of the literature. ArchP athol LabMed1981 Oct; 105(10): 532-5.

4. Vargas H, Jennings TA, Galati LT. Unusal paranasal sinus tumours intwo patients with common nasal complaints.Ear Nose Throat J.2001Oct;80(10)724-6,728-9.

5. Fowler MR, Williams RB,Alba JM and Byrd CR. Extra adrenalmyelolipomas compared with extramedullary hematopoietic tumors:a case of presacral myelolipoma. AM j SurgPathol1982 Jan; 6(4): 363-74.

6. Dariusz S, Malgorzata Z, ElzbietaK. Primarymyelolipoma of thechest wall. Ann Thorac Surg 2009;88;e39-41.

7. Ackerman LV. Common errors made by pathologists in the diagnosis of bone tumors. Recent Results Cancer Res 1976;(54):120-38

8. Rosai and Ackerman Surgical Pathology 2 Volume, $10^{\text {th }}$ Edition.

9. Kristensen S. Cervical hibernoma: Review of literature anda new case. J Laryngol Otol. 1985 Oct; 99(10):1055-8.

10. Gery L. Discussions. Bull MemSocAnat (Paris).1914;89:111.

11. World Health Organization, Classification of Tumors, Pathology and Genetics of Tumors of Soft tissue and bone.

12. Baldi A, Santini M, Mellone P, et al. Mediastinalhibernoma:a case report. J ClinPathol. 2004 Sep;57(9):993-4. 